REVISTA DE LA CEPAL 82 . ABRIL 2004

\title{
Una propuesta de gravar con impuestos unitarios las ganancias
}

\section{de las empresas transnacionales}

\author{
Andrew Mold
}

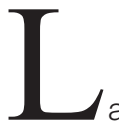

inversión extranjera directa en los países en desarrollo ha venido creciendo a un ritmo sin precedentes, y la rentabilidad de los negocios de las empresas extranjeras que invierten en regiones pobres, como el África subsahariana, es extraordinariamente alta. No obstante, las empresas transnacionales pagan cada vez menos impuestos, perjudicando en particular a los países en desarrollo: se ha estimado que estos pierden ingresos de por lo menos 35.000 millones de dólares anuales debido a prácticas de evasión fiscal. En este artículo, que presenta evidencia empírica, se propone aplicar un sistema de impuestos unitarios a las ganancias de las empresas transnacionales, que eliminaría uno de sus mecanismos más eficaces de elusión tributaria: la asignación de precios de transferencia. Se concluye que una propuesta de crear un sistema de impuestos unitarios a nivel mundial puede destrabar las División de Comercio e Integración Regional, Comisión Económica de las Naciones Unidas para África Adis Ababa, Ethiopia

$\rightarrow$ andymold2003@yahoo.com negociaciones relativas a un código multilateral sobre inversiones. 


\section{I}

\section{Introducción}

Después de una década perdida de ajuste estructural y reducción del gasto público, se reconoce cada vez más que los países en desarrollo deberían buscar nuevas fuentes de ingresos. Recientemente se estimó, por ejemplo, que en tales países existe una diferencia de hasta 80.000 millones de dólares anuales entre lo que se gasta y lo que se debería gastar para garantizar el acceso universal a servicios básicos de salud y educación (Mehrotra, Vandemoortele y Delamonica, 2000). Sin embargo, como resultado de la presión constante que ejercen las instituciones financieras internacionales para que se reduzcan los gastos, la capacidad de los Estados para prestar esos servicios se ha debilitado enormemente en muchas regiones.

En efecto, en algunos países los ingresos son tan bajos que el Estado corre peligro de desintegrarse. En Guatemala, por ejemplo, el gasto público alcanza apenas al $10 \%$ del PIB, y el gobierno aparentemente ha renunciado a toda pretensión de cumplir sus obligaciones en lo que respecta a la prestación de servicios sociales básicos, y ha delegado todas sus responsabilidades de esa índole en las organizaciones no gubernamentales (ONG); evidentemente, esta es una función que las ONG no están bien preparadas para desempeñar. En una línea similar, refiriéndose al caso de México, el ex Presidente del Uruguay Julio María Sanguinetti preguntó recientemente "¿cómo es posible llevar a cabo programas sociales en Chiapas cuando la presión fiscal del Estado mexicano equivale únicamente al 10\% del PIB?". ${ }^{1}$ Lo irónico del asunto es que estas tendencias han coincidido con un consenso cada vez mayor en cuanto a la necesidad de fortalecer la capacidad del Estado y de las instituciones si se desea avanzar en la erradicación de la pobreza. Las instituciones financieras internacionales y los gobiernos de muchos países donantes están haciendo hincapié de manera creciente en que las instituciones funcionen bien y en imponer condiciones respecto a la gobernabilidad, pero parece haber poca disposición a encontrar nuevas formas de proporcionar la financiación necesaria para respaldar esos cambios.

En un contexto como el que acaba de describirse, parece lógico que se haga mayor hincapié en las estrategias de generación de ingresos. Ha habido

\footnotetext{
${ }^{1}$ Véase El país, 2001, p. 7
}

propuestas ambiciosas de crear impuestos para ayudar a financiar el desarrollo (como el impuesto Tobin), que aparentemente han quedado por el camino, en parte debido a dudas sobre su eficacia, y en parte debido sencillamente a una falta de voluntad política de presionar para que se aprueben las propuestas. ${ }^{2}$ Por otra parte, se ha prestado poca atención a la posibilidad de incrementar los ingresos fiscales mediante la aplicación de un régimen tributario más eficiente a las actividades de las empresas transnacionales. Las corrientes de inversión extranjera directa (IED) hacia países en desarrollo se han cuadruplicado con creces desde principios de la década de 1990, pasando de un promedio de 47.000 millones de dólares en 1988-1993, a 238.000 millones de dólares en 2000 (UNCTAD, 2002, anexo, cuadro B.1.). La globalización creciente de la producción internacional confiere enormes beneficios a las empresas transnacionales. Con las facilidades que les han otorgado la liberalización y los programas de ajuste estructural, han podido entrar en mercados nuevos de países en desarrollo y han participado en programas de privatización, comprando activos públicos a menudo a precios sumamente favorables. En vista de las oportunidades disponibles, y contrariamente a la opinión popular, la rentabilidad en las regiones en desarrollo puede ser extraordinariamente alta. Los datos correspondientes a sociedades estadounidenses revelan que la rentabilidad media de las actividades de estas empresas en el África subsahariana en los últimos cinco años superó el 25\% (Mold, 2001). En otras palabras, ellas recuperan la inversión inicial en solamente cuatro años. Es evidente que la globalización ha sido beneficiosa para las empresas transnacionales más grandes.

Sin embargo, hay indicios de que el auge de la IED ha ido acompañado de una habilidad cada vez mayor de esas empresas para eludir el pago de impuestos en las jurisdicciones en las que desarrollan sus actividades. Algunas de esas evidencias son anecdóticas. Por ejemplo, hace unos pocos años se reveló que Newscorp Investments, una sociedad de cartera (holding) con 101 filiales de propiedad del magnate australiano de los medios de difusión Rupert Murdoch, había generado ganancias por valor de 1.400 millones de libras esterlinas

\footnotetext{
${ }^{2}$ En Haq, Kaul y Grunberg (1996) puede verse un análisis de los aspectos prácticos en juego.
} 
desde junio de 1987, pero que en términos netos no había pagado absolutamente nada al Reino Unido por concepto de impuesto sobre las sociedades (The Economist, 1999). Es evidente que esta situación se explica por el intenso uso hecho por esa sociedad de lagunas tributarias que permiten ocultar las ganancias bajo el manto protector de los paraísos fiscales.

Newscorp Investments dista mucho de ser un ejemplo aislado. Un estudio sistemático realizado en los Estados Unidos (McIntyre y Nguyen, 2000) reveló que algunas empresas muy conocidas -como Goodyear, Texaco, Colgate-Palmolive, MCI WorldCom y otras ocho grandes compañías- habían ganado más de 12.200 millones de dólares en el período 1996-1998, pero que ninguna de ellas había pagado impuestos sobre los ingresos de las sociedades en los Estados Unidos en ese mismo período. De las 250 grandes empresas que cotizaban en la bolsa analizadas en el estudio mencionado, 24 no debían impuestos o habían recibido créditos fiscales por el pago de obligaciones tributarias pasadas o futuras en 1998, y 71 pagaron impuestos a una tasa inferior a la mitad de la tasa oficial de $35 \%$ del impuesto sobre las sociedades durante ese trienio. De manera similar, un estudio realizado por Altshuler, Grubert y Newlon (1998) acerca de las tasas impositivas efectivas pagadas en el extranjero por filiales de grandes empresas manufactureras estadounidenses reveló que las tasas medias habían descendido en más de 15 puntos porcentuales entre 1984 y 1992.

Los países en desarrollo son particularmente vulnerables a este tipo de estrategias de evasión de impuestos. Si bien el grado de presión fiscal suele ser menor que en los países industrializados, su capacidad institucional de fiscalización de la evasión fiscal es mucho más reducida. Generalmente carecen de información suficiente sobre la sociedad matriz como para poder impugnar la fijación de precios de transferencia y otros mecanismos de evasión fiscal. Gran parte de IED que reciben se concentra en sectores como la industria del petróleo, los artículos electrónicos y los productos forestales, donde las posibilidades de evadir impuestos son grandes. Dado que una proporción considerable del comercio total de los países en desarrollo está bajo el control de empresas transnacionales, dichos países suelen ser más vulnerables a las prácticas de evasión fiscal basadas en la sobrefacturación o subfacturación de importaciones y exportaciones.

Además, en muchos países en desarrollo las bajas tasas del impuesto sobre las sociedades, combinadas con el amplio uso de reducciones de impuestos o de exoneraciones temporales de impuestos para atraer la inversión extranjera, han permitido a las empresas transnacionales reducir enormemente sus obligaciones tributarias. Uno de los casos más extremos es el de las 15 zonas francas para la industria de exportación o zonas de libre comercio creadas en Honduras, donde se ha otorgado a las empresas extranjeras una exención permanente de todos los impuestos. Sin embargo, las exoneraciones de impuestos por períodos de 10 a 20 años son actualmente algo bastante común en los países en desarrollo. ${ }^{3}$ Sri Lanka, por ejemplo, tiene seis zonas francas para la industria de exportación (ZPE) que han sido liberadas por 10 a 20 años del pago de impuestos en el caso de grandes proyectos nuevos de exportación o de determinadas industrias. Tales iniciativas persisten, a pesar de que está surgiendo un consenso en cuanto a que, desde la perspectiva del desarrollo, este tipo de medidas son ineficaces o incluso contraproducentes en el largo plazo. ${ }^{4}$

Las tendencias descritas deberían obligar a las autoridades encargadas de formular las políticas a considerar otros métodos de generación de ingresos. Es indudable que el sistema actual está fallando en lo que respecta a la equidad. Esto es verdad tanto desde el punto de vista de lo que podríamos llamar equidad interna, como desde el punto de vista de la equidad internacional. Falla la equidad interna porque dentro de cada país los asalariados tienen que financiar cada vez más con sus impuestos la mayor parte del gasto público, mientras el capital con movilidad internacional se beneficia por la reducción de las tasas impositivas efectivas; y falla la equidad internacional en la medida en que hay pruebas de que los impuestos sobre los ingresos recaudados en relación con las actividades de las empresas transnacionales han venido disminuyendo más rápidamente en los países en desarrollo que en los países industrializados. En efecto, los únicos "ganadores" en todo esto son las propias empresas transnacionales, y los paraísos fiscales con tasas impositivas efectivas más bajas. Por consiguiente, mientras el volumen de la IED en todo el mundo se ha multiplicado aproximadamente por 10 en el período comprendido entre 1980 y 2000, en las Islas Caimán se ha multiplicado por más de 100, hasta alcanzar los 24.900 millones de dólares. Con una población de apenas 36.000 habitantes,

\footnotetext{
${ }^{3}$ Una lista de algunas zonas francas industriales de países en desarrollo elaborada por la UNCTAD (1999, anexo, cuadro A.IX.3) revela un total de 16 de esas zonas que otorgan exenciones tributarias con carácter general, y otras 15 que aplican un período de exoneración tributaria de 10 a 20 años.

${ }^{4}$ Véase, por ejemplo, el artículo de los economistas del FMI Zee, Stotsky y Ley (2002).
} 
esto representa la cifra astronómica de 700.000 dólares de inversión extranjera por habitante. De manera similar, el volumen de inversión en las Bermudas aumentó en 10.000 millones de dólares en apenas un año, de 2000 a 2001, y actualmente asciende en total a más de 66.000 millones de dólares. Si ponemos esta cifra en perspectiva, vemos que supera los 50.000 millones de dólares en inversiones realizadas en todo el Japón y que, para una población de sólo 64.000 habitantes, representa más de 1 millón de dólares por habitante (UNCTAD, 2002, cuadro B.3).

Más allá del fraude liso y llano, uno de los métodos principales que utilizan las empresas transnacionales para trasladar sus ingresos a jurisdicciones con impuestos bajos y de esa manera reducir las tasas impositivas efectivas, es el de recurrir a los precios de transferencia. Mediante la manipulación de los precios en las transferencias de bienes y servicios dentro de una misma empresa se busca disminuir las obligaciones tributarias en los países que tienen altas tasas impositivas marginales, y aumentar las ganancias en los países donde las obligaciones tributarias son bajas. Más del $80 \%$ de las empresas transnacionales incluidas en un estudio admitieron haber sido objeto en algún momento de una investigación sobre sus precios de transferencia por parte de autoridades tributarias locales o extranjeras. ${ }^{5}$ Si bien se trata en principio de una práctica ilícita, en los hechos es muy difícil para las autoridades impositivas controlar el manejo de los precios de transferencia. Con respecto a muchas de las transferencias dentro de una misma empresa, es muy difícil para las autoridades locales establecer un precio de mercado "correcto". Por ejemplo, algunos tipos de componentes o productos intermedios pueden estar fácilmente disponibles en el mercado abierto, de modo que no cuesta mucho comparar el precio pagado por una filial con el precio del mercado abierto. En cambio, hay otros productos que, por ser específicos de una determinada empresa, son imposibles de evaluar en función de un "precio de mercado". Esto plantea un dilema a las autoridades tributarias. ¿Cómo deberían estimar el precio "correcto" de un producto comercializado entre filiales de una misma empresa? Estas dificultades se agudizan si se considera que las empresas transnacionales comparten toda clase de recursos de gestión e innovación (como patentes, por ejemplo). El carácter intangible de estos bienes y servicios determina que en la práctica sea imposible distribuir los costos con exactitud entre las distintas filiales. En consecuencia, no sorprende que

\footnotetext{
5 Eden (1998).
}

las empresas transnacionales tengan amplia libertad para ajustar los precios cobrados internamente de manera de reducir al mínimo sus obligaciones tributarias. Pese a todas estas dificultades, las autoridades impositivas se aferran al principio de que cada filial de tales empresas debe ser considerada una unidad independiente.

Por supuesto que, en la práctica, siempre ha sido una ficción considerar que las diversas filiales de una empresa transnacional son entidades autónomas. Como ha comentado Vernon (1998, p.40), 'en el mundo real, las ganancias asignadas a cada país por una empresa transnacional son normalmente un artificio cuya magnitud se determina principalmente en función de los precedentes y de la capacidad de argumentación de los abogados y contadores'. ${ }^{6}$ Sin embargo, en un mundo cada vez más globalizado, en el que las filiales quedan cogidas en la trama internacional de la empresa, esta ficción se está volviendo insostenible con rapidez. Como demostraremos a continuación, es también una ficción muy onerosa para los países receptores.

En este breve ensayo se formula una propuesta de crear un sistema diferente para gravar las utilidades de las empresas transnacionales: los impuestos unitarios. En pocas palabras, los regímenes impositivos unitarios aplican algún método nocional de asignación de las utilidades mundiales, en lugar de basarse en las ganancias declaradas por cada una de las filiales. Esto tiene sentido porque el objetivo de las empresas transnacionales es maximizar las ganancias del grupo: a los administradores de las empresas normalmente les es indiferente el lugar de la red transnacional en el que esas ganancias se generan. En un sistema de impuestos unitarios, el monto de los impuestos sobre las ganancias que debería pagarse en cada país se determinaría de acuerdo con algún criterio, como la participación de cada filial en las ventas, los empleos o los activos a nivel mundial. ${ }^{7}$

\footnotetext{
${ }^{6}$ En este artículo, las comillas simples indican que la cita ha sido traducida del original.

${ }^{7}$ Se corre un riesgo al incluir la mano de obra en la fórmula de prorrateo. La adopción de un sistema de impuestos unitarios no impide a los países gravar a las sociedades con tasas impositivas diferentes. Por lo tanto, en los países cuyas tasas de impuesto sobre las sociedades son relativamente altas, una fórmula de prorrateo basada en el empleo puede dar a las empresas transnacionales un incentivo perverso para sustituir la mano de obra por capital, exagerando un sesgo que ya existe en esas empresas porque tienen acceso a capital relativamente barato. En Goolsbee y Maydew (1998) se citan pruebas de este hecho, derivadas de la experiencia de los Estados Unidos. En vista de la prioridad que se asigna a la creación de empleos tanto en los países en desarrollo como en los países industrializados, tal vez sea mejor basar los impuestos unitarios en otro indicador, o en una combinación de diversas variables (véase la sección IV).
} 
Es evidente que un sistema de esta índole no eliminaría todas las formas de evasión fiscal. De todos modos habría que tomar medidas para contrarrestar la multiplicidad de métodos de evasión (ilícita) de impuestos. Las prácticas contables fraudulentas, como las que quedaron de manifiesto en los escándalos de la Worldcom y la Enron en los Estados Unidos, seguirían creando problemas. ${ }^{8}$ No obstante, un sistema unitario reduciría enormemente la capacidad de las empresas transnacionales para transferir ganancias a su antojo de un lugar a otro, permitiría una mayor transparencia, y contribuiría a incrementar la recaudación fiscal total, liberando recursos que podrían destinarse a lograr objetivos de desarrollo como la prestación universal de servicios básicos de salud y educación. Aunque puedan mostrarse renuentes a admitirlo, un sistema de este tipo podría incluso generar beneficios a largo plazo para las propias empresas transnacionales, pues al reducir la necesidad de dedicar tiempo y recursos administrativos valiosos a la búsqueda de formas de minimizar sus obligaciones tributarias, les permitiría dedicarse más a acrecentar las fortalezas competitivas de sus empresas.

\section{II}

\section{Evidencias de la evasión de impuestos por las empresas transnacionales}

Diversos estudios de los factores determinantes de la IED tanto en los países en desarrollo como en los países industrializados revelan que las empresas transnacionales generalmente asignan gran valor a lugares que tienen buena infraestructura, mano de obra calificada, normas sociales de alta calidad, etc. ${ }^{9}$ Por ser todos ellos bienes públicos, son los gobiernos los que están en mejores condiciones de proporcionarlos. Sin embargo, al mismo tiempo, dichas empresas parecen estar cada vez más reacios a contribuir al financiamiento de esos bienes públicos. En los Estados Unidos, por ejemplo, los impuestos sobre los ingresos de las sociedades como porcentaje de las ganancias brutas disminuyeron de más del $40 \%$ a principios del decenio de 1960 , a un promedio de sólo 21,5\% entre 1990 y 1996 (Poterba, 1999, cuadro 3)..$^{10}$ En 1952, los impuestos sobre los ingresos de las sociedades representaban el $32 \%$ del

\footnotetext{
${ }^{8}$ Lo que sin duda resulta irónico es que, como ambas empresas inflaban artificialmente sus ganancias reales, tanto la Enron como la Worldcom tenían que pagar más impuestos -los que perdían en este caso eran principalmente los accionistas de las sociedades en cuestión. En Bayliss y Hall (2001) figura un análisis crítico profético de las actividades de la Enron justo antes de que estallara el escándalo. 9 En Mold (2000) se pasa revista ampliamente a estudios econométricos de los factores que determinan la ubicación de la IED. ${ }^{10}$ Por lo menos en el caso de los Estados Unidos, puede ser erróneo atribuir esta disminución de las tasas impositivas sobre los ingresos de las sociedades a tendencias relacionadas con la globalización; al parecer, la causa principal sería la aprobación de la Ley de recuperación económica de 1981, que determinó una brusca reducción de dichas tasas (Poterba, 1999, p.13).
}

total de los ingresos tributarios del gobierno federal de los Estados Unidos, mientras que en 1999 representaron solamente el 10\% (Weisbrot, Naiman y Kim, 2000, p.15). En la Organización de Cooperación y Desarrollo Económicos (OCDE), los impuestos sobre las sociedades representan actualmente sólo el $8 \%$ de los ingresos fiscales, lo que equivale apenas al 3\% del PIB (Fitzgerald, 2001, p.7).

La globalización ha facilitado esa reducción tan importante de las tasas impositivas básicamente de dos maneras. En primer lugar, el intercambio comercial cada vez mayor que se produce dentro de una misma empresa (es decir, entre las filiales y la compañía matriz) mejora las posibilidades que tienen las empresas con actividades internacionales de transferir las ganancias de una jurisdicción fiscal a otra. El intercambio comercial dentro de las empresas representa hoy en día aproximadamente la tercera parte de todo el comercio mundial. Esto crea enormes problemas a las autoridades tributarias nacionales, debido al uso de precios de transferencia por las empresas transnacionales y a la probabilidad de que ellas manipulen esos precios para trasladar las ganancias a jurisdicciones que tienen impuestos bajos. Además, como observa Tanzi (2000, p.18), 'en virtud de los regímenes tributarios actuales, es probable que este problema se agrave. Las autoridades impositivas de muchos países están hoy en día preocupadas por esta tendencia, pero a menudo no saben qué hacer al respecto'. 
El otro medio al que recurren las empresas transnacionales para reducir la tasa efectiva de los impuestos que pagan consiste en presionar a los gobiernos para que rebajen los gravámenes al capital con movilidad internacional. Los gobiernos aplican cada vez más políticas para atraer la inversión extranjera. Desde 1991 en adelante, 58 países han comenzado a adoptar políticas de promoción de las inversiones, con lo que el número de países que actualmente las aplican asciende a 116 (Moran, 1998, p.37). Una de las medidas más utilizadas para atraer inversiones extranjeras son las concesiones tributarias. Como se señala en un informe de la Organización Internacional del Trabajo (огт), 'en un mundo caracterizado por una tendencia decisiva a la "globalización", donde la liberalización del comercio y las corrientes de capital adquieren un predominio creciente, la tentación de los Estados nacionales de embarcarse en una "desgravación competitiva" y una "desregulación competitiva" es evidente' (огт, 1997, p.70). En efecto, hay un creciente temor de que este proceso esté degenerando en una perjudicial carrera descendente, que lleve a un deterioro gradual de la base imponible de los Estados y a que el peso tributario restante recaiga desproporcionadamente sobre factores no móviles, en particular la mano de obra (Kozul-Wright y Rowthorn, 1998; Radaelli, 1999). ${ }^{11}$

Esta tendencia puede verse claramente en las tasas establecidas por ley del impuesto sobre las sociedades. Anteriormente, los países solían gravar el ingreso neto de las sociedades con tasas marginales que oscilaban entre el 30\% y el 50\% (Caves, 1996, p.189). Además, no había grandes diferencias entre las tasas del impuesto a las sociedades que aplicaban los países en desarrollo y los países industrializados. En cambio, hoy en día hay evidencias de que la brecha entre las tasas vigentes en la OCDE y las vigentes en los países en desarrollo se está ensanchando. Pocos países en desarrollo aplican a las sociedades tasas impositivas superiores al $20 \%$. Según estimaciones de Oxfam (2000), si los países en desarrollo aplicaran las mismas tasas impositivas que la OCDE, recaudarían por lo menos 35.000 millones de

\footnotetext{
${ }^{11}$ Por supuesto que este temor no es nuevo. Hace treinta años, un artículo de Bergsten fue particularmente profético al respecto: 'A muchas inversiones les es prácticamente indiferente su localización y por ende son cercanas a juegos de suma cero; en esos casos, una decisión que beneficia a una parte, perjudica a la otra. Además, el bienestar mundial de hecho puede disminuir como resultado de algunas inversiones extranjeras, como las que son inducidas principalmente por el trato impositivo preferencial ofrecido por el país receptor' (Bergsten, 1974, p.145)
}

dólares más. ${ }^{12}$ Los cambios son aún más notorios cuando se calculan las tasas impositivas efectivas. ${ }^{13}$ Por ejemplo, los cálculos realizados para este estudio con datos correspondientes a filiales de propiedad mayoritaria de empresas estadounidenses revelan que, a nivel mundial, las tasas impositivas efectivas medias que pagan esas empresas han disminuido del 49,6\% de los ingresos antes de deducir los impuestos en 1983, a solamente el 23,3\% en 1998 (apéndice y gráfico 1).

\section{GRAFICO 1 \\ Países desarrollados y en desarrollo: Tasas impositivas efectivas pagadas por filiales de propiedad mayoritaria de empresas estadounidenses,1983 y 1999}

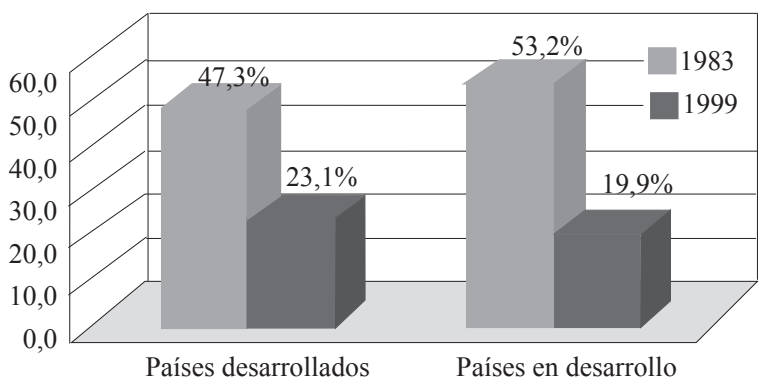

Fuente: Elaboración propia con datos del Departamento de Comercio de los Estados Unidos (véase apéndice).

En la medida en que estas cifras tiendan a subestimar considerablemente el verdadero monto del ingreso antes de deducir los impuestos, es probable que las tasas impositivas efectivas reales sean aún menores. Además, mientras que en 1983 las tasas impositivas

\footnotetext{
12 Esta cifra se calculó utilizando un acervo estimado de IED hacia los países en desarrollo de 1.219 mil millones de dólares. Se supuso que ese acervo de inversión tenía una tasa de rendimiento del $20 \%$, y que la tasa impositiva era la comúnmente utilizada en la OCDE, de $35 \%$. Sobre esa base, los países en desarrollo deberían estar percibiendo ingresos fiscales de las sociedades extranjeras por un valor aproximado de 85.000 millones de dólares anuales, pero en los hechos reciben como máximo alrededor de 50.000 millones de dólares. Sin embargo, los autores del estudio mencionado reconocen que ésta es probablemente una estimación muy conservadora, ya que las cifras oficiales no sólo tienden a subestimar el verdadero valor de la IED, sino que no tienen en cuenta las transacciones financieras de las empresas más grandes.

13 Las tasas impositivas efectivas se definen como la relación entre los impuestos extranjeros sobre los ingresos y los ingresos brutos (la suma de los ingresos netos más los impuestos extranjeros sobre los ingresos). Si una tasa nominal alta del impuesto sobre las sociedades va acompañada de generosas exenciones, puede surgir una gran discrepancia entre las tasas nominales y las efectivas. Desde el punto de vista de las empresas, lo que importa es obviamente la tasa efectiva.
} 
efectivas eran marginalmente superiores en los países en desarrollo que en los países industrializados, hacia 1998 esa relación se había invertido y las tasas efectivas eran en promedio más altas en los países desarrollados $(19,9 \%$ contra $23,1 \%) .{ }^{14}$ Otro aspecto que se destaca en las cifras calculadas en el apéndice es la gran dispersión de las tasas impositivas efectivas. En efecto, mientras que en países como Nigeria o Indonesia esa tasa era en 1999 de $53,3 \%$ y $32,2 \%$, respectivamente, en Luxemburgo, las Bermudas, Panamá o Suiza las cifras respectivas sólo alcanzaban a 2,5\%, 2,8\%, 0,5\% y $5,7 \%$. El incentivo para transferir las ganancias antes de deducir los impuestos a estas últimas jurisdicciones impositivas es sin duda muy fuerte. ${ }^{15} 16$

\section{III}

\section{Las consecuencias para los países}

\section{en desarrollo}

Las repercusiones de esta "guerra por inversiones" en lo que respecta a reducir la recaudación fiscal total, pueden ser muy perjudiciales para los países en desarrollo. Las reducciones de impuestos y las exoneraciones temporales de impuestos son cada vez más generosas. En algunos países, como Honduras, Jamaica, Namibia y Senegal, se ha otorgado a las empresas exenciones tributarias permanentes. Las exoneraciones temporales de impuestos en las zonas francas industriales se han extendido en algunos casos hasta 20 años. Sin embargo, una de las ironías de ofrecer reducciones de impuestos cada vez más generosas es que los efectos de las regulaciones impositivas sobre

\footnotetext{
${ }^{14}$ Estos resultados se asemejan, en términos generales, a las conclusiones de un estudio realizado por Altshuler, Grubert y Newlon (1998) acerca de las tasas impositivas efectivas medias que pagan las grandes empresas manufactureras estadounidenses. Ese estudio se basó en datos del Tesoro de los Estados Unidos sobre los impuestos a las sociedades en el período comprendido entre 1980 y 1992 , encontró que las tasas habían caído más de 15 puntos porcentuales entre 1984 y 1992. La disminución de las tasas impositivas efectivas fue particularmente pronunciada en muchos países en desarrollo. ${ }^{15}$ Algunas regiones en desarrollo, en particular África, parecen tener tasas impositivas efectivas muy altas. Sin embargo, estas cifras no reflejan necesariamente tasas totales altas, sino más bien el hecho de que las inversiones se dirigen a sectores (principalmente la industria petrolera y la minería) donde la proporción de los ingresos brutos que retiene el gobierno receptor es relativamente alta. Por ejemplo, en Nigeria, mientras que la tasa efectiva aplicable a todas las industrias era de $32,4 \%$, según el estudio de Altshuler, Grubert y Newlon (1998) la correspondiente a empresas manufactureras estadounidenses en Nigeria era de solamente 13\%. Las altas tasas impositivas aparentes aplicables a los sectores del petróleo y la minería pueden ser también el resultado de un extendido manejo de los precios de transferencia, que da una falsa impresión de las tasas impositivas efectivas reales.
}

las decisiones de localización de las empresas son ambiguos. Por ejemplo, un estudio detallado de Wells y Allen (2002) sobre la eliminación de las exoneraciones temporales de impuestos en Indonesia no reveló ningún efecto observable en la capacidad posterior del país de atraer corrientes importantes de inversión extranjera. De manera similar, en un estudio econométrico de las decisiones adoptadas por empresas manufactureras estadounidenses y japonesas de instalarse en 74 países receptores, Kumar (1999) encontró muy pocas pruebas de que las tasas impositivas más bajas o los incentivos tributarios influyeran en la decisión de producir en países en desarrollo. De hecho, los resultados de algunas

\footnotetext{
${ }^{16}$ Aquí es preciso hacer una salvedad importante. Algunos países que son fuentes importantes de IED otorgan créditos por impuestos pagados en el extranjero, que pueden deducirse de la renta imponible. Por ejemplo, el Gobierno de los Estados Unidos obtiene muy pocos ingresos por concepto de impuestos sobre las sociedades estadounidenses ubicadas en países con impuestos altos, ya que las ganancias gravadas por impuestos en esos países generan créditos fiscales que compensan cualquier obligación tributaria residual en los Estados Unidos. En cambio, una proporción elevada, aproximadamente el $40 \%$, de los ingresos que obtienen los Estados Unidos al gravar las ganancias de las empresas estadounidenses en el exterior, provienen de los impuestos sobre las ganancias que obtienen dichas empresas en los paraísos fiscales (Hines y Rice, 1994, p.150). Por lo tanto, los sistemas de créditos fiscales pueden tener como resultado perverso que el inversionista deba pagar impuestos más altos en su país de origen. Debido a este fenómeno, en algunos círculos las exenciones temporales de impuestos comienzan a conocerse como "ayuda extranjera inversa" (Wells y Allen, 2002, p.8). Sería interesante extender nuestro análisis a países que no otorgan créditos fiscales amplios, como Francia; en esos casos cabría esperar que hubiera un incentivo mucho mayor para transferir las ganancias a jurisdicciones con impuestos bajos.
} 
de las regresiones de Kumar parecen sugerir que la existencia de tasas impositivas más altas estaba relacionada positivamente con niveles de producción más elevados de las filiales de empresas extranjeras. ${ }^{17}$ Si bien hay por cierto casos individuales en los que las tasas impositivas han influido en la decisión final, en general las empresas transnacionales parecen encarar las decisiones de localización con una perspectiva de largo plazo, y es más probable que se dejen influir por factores como la calidad de la infraestructura local, la disponibilidad de mano de obra calificada y, probablemente lo más importante de todo, un mercado local dinámico.

Conclusiones como confieren credibilidad a la idea de que los gobiernos han hecho demasiadas concesiones a las empresas transnacionales a cambio de demasiado poco -la competencia tributaria no es ni siquiera un método muy eficaz de atraer inversión extranjera de largo plazo. En realidad, hay otras formas más eficaces de atraer IED en lugar de tener que depender de las reducciones de impuestos. Se ha sugerido, por ejemplo, que una política más conveniente sería la de respaldar la inversión en capital humano, educación o capacidad tecnológica local (MacEwan, 2001, pp.299300). De esa manera, si la filial en definitiva cierra, o se va a otro país que tenga una tasa impositiva más baja, el gobierno conserva por lo menos el beneficio de la inversión inicial en términos de una mano de obra más calificada, o una mejor infraestructura. Si el único incentivo que se ofrece es una tasa impositiva baja, se pierde todo si la empresa finalmente decide instalarse en otro lugar.

Además, a pesar del gran entusiasmo que han mostrado las autoridades encargadas de formular las políticas, probablemente sean limitados los beneficios potenciales para los países en desarrollo -como grupoque deriven de la obtención de IED mediante reducciones de impuestos y exoneración temporal de impuestos. Por ejemplo, se ha estimado que el empleo total en las zonas francas para la industria de exportación (ZPE) de los países en desarrollo no supera los 4 millones (Dicken,

\footnotetext{
${ }^{17}$ En Morriset y Pirnia (2002) figura un examen reciente de estos estudios. Es verdad que en algunos estudios aún más recientes sí se ha encontrado una relación entre la presión fiscal y los estudios de inversión; mucho parecería depender de la forma en que se define la variable impositiva en el análisis de regresión (las tasas impositivas efectivas parecerían tener una capacidad explicativa mucho mayor que las tasas impositivas nominales). Sin embargo, como reconoce Hines (1996a, p.8), incluso en esos estudios la influencia de las tasas impositivas en la localización y el volumen de las inversiones tiende a ser relativamente pequeña.
}

1998, p.131). ${ }^{18}$ Los empleos en esas zonas generalmente no representan más del $5 \%$ de la mano de obra total ocupada en el sector manufacturero de los países en desarrollo, cifra muy pequeña si se compara con los 300 millones de personas que, según se estima, trabajan en los "sectores informales" (Madeley, 1999, p.113). Si se considera que existe una cantidad estimada de 1.200 millones de personas que viven con menos de 1 dólar por día, es obvio que el impacto potencial de las ZPE en la reducción de la pobreza es limitado. ${ }^{19}$ Tampoco es una coincidencia que, con la excepción de México y China, los países en desarrollo que han hecho el mejor uso de estas prácticas para atraer inversiones extranjeras tiendan a ser Estados insulares relativamente pequeños, como Mauricio. En síntesis, en calidad de modelos que otros países en desarrollo podrían imitar, la importancia de las zPE es limitada. Al examinar la información al respecto, un grupo de economistas del Fondo Monetario Internacional (FMI) admitió que 'la creación y/o el mantenimiento de zonas francas para la industria de exportación no suele ser aconsejable' (Zee, Stotsky y Ley, 2002, p.1507). Sin embargo, los gobiernos de los países en desarrollo le han asignado un monto importante de fondos escasos, y han renunciado a una cantidad considerable de ingresos fiscales, con la esperanza de atraer empresas hacia esas zonas.

Por supuesto, la propuesta de reavivar el debate sobre los impuestos unitarios que se formula en este artículo poco puede hacer para evitar la competencia tributaria y "guerras para atraer inversiones". Ante este problema obviamente se precisa una mayor coordinación entre las autoridades tributarias. Sin embargo, la manipulación de los precios de transferencia sí puede combatirse con impuestos unitarios. Los países en desarrollo son particularmente susceptibles a ese tipo de maniobras. Gran parte de su acervo de inversiones se concentra en las industrias primarias. Hay sectores como el del petróleo que son famosos por su habilidad para mover fondos hacia adentro y hacia fuera de los países. El manejo de los precios de transferencia se ve facilitado por el gran volumen de transacciones

\footnotetext{
${ }^{18}$ Además, esos empleos tienen una alta concentración geográfica. México por sí solo ofrece 600.000 empleos en las zPE. China también es responsable de una alta propoción del empleo total en la ZPE . La gran mayoría de los países en desarrollo tienen una participación insignificante en los empleos generados por las ZPE. ${ }^{19}$ Es evidente que la entrada de empresas extranjeras puede generar toda clase de efectos indirectos potenciales, pero no hay una garantía automática de que esos efectos positivos indirectos se vayan a producir.
} 
transfronterizas que tienen lugar en los sectores de la minería y el petróleo. Por otra parte, las autoridades fiscales de los países en desarrollo no tienen la misma capacidad que las de los países desarrollados para fiscalizar esas maniobras.

Hay otros incentivos que llevan a las empresas transnacionales a embarcarse en una intensa manipulación de los precios de transferencia en los países en desarrollo. Si bien en el pasado los impuestos sobre las ganancias en estos países tendían a ser más bajos que en los industrializados, el nivel de los aranceles ad valorem sobre el comercio sigue siendo generalmente más alto en los países en desarrollo. Al subfacturar el costo real de las importaciones o exportaciones dentro de una misma compañía, las empresas transnacionales suelen manipular los precios de transferencia para reducir al mínimo los pagos por concepto de aranceles sobre el comercio. Por su parte, como forma de promover la reinversión de las ganancias en la economía receptora, los gobiernos de los países en desarrollo tradicionalmente han impuesto más restricciones a la repatriación de las ganancias que los países desarrollados. Frente a tales restricciones, sin embargo, vemos que el mecanismo de los precios de transferencia ha proporcionado a las empresas transnacionales otra forma de sacar ingresos de un país (Grimwade, 2000, p.149).

¿Hasta qué punto se utilizan realmente las posibilidades de manipulación de los precios de transferencia en detrimento de los países en desarrollo? La mayoría de los estudios empíricos sobre este tema datan de los decenios de 1970 y 1980 . No obstante, como observa Elson (1995, p.305), las pocas investigaciones sistemáticas que se han realizado han demostrado -todas ellas-, que los precios de transferencia se usan en perjuicio de los países en desarrollo. Por ejemplo, un estudio temprano de la industria farmacéutica de Colombia realizado por Vaitsos (1977) reveló que las ganancias declaradas representaban apenas el 3,4\% de la rentabilidad efectiva; las regalías el $14,0 \%$, y la asignación de precios superiores a los reales el $82,6 \%$. Se estimó que el costo adicional de las importaciones de productos farmacéuticos solamente, en la economía colombiana, era de 20 millones de dólares anuales. Además, cuando se manipulaban los precios de transferencia para declarar ganancias inferiores a las reales, los gobiernos sufrían una pérdida importante de ingresos fiscales, del orden de los 10 millones de dólares anuales. Investigaciones realizadas por Lall y Streeten (1977, p.153) confirmaron esta práctica sistemática de la industria farmacéutica de Colombia de asignar a las importaciones precios superiores a los reales: a determinados artículos, según se descubrió, se les asignaban precios que superaban a los reales en $5.000 \%$ a $6.000 \%$. Estas prácticas también predominaban en la industria del caucho y la electricidad. Los estudios más recientes han tendido a concentrarse en comparaciones de los niveles de rentabilidad antes de deducir los impuestos como medida indirecta de la actividad de asignación de precios de transferencia. Un estudio amplio de la rentabilidad de las filiales estadounidenses en 59 países receptores realizado por Hines y Rice (1994), sobre la base de datos de 1982, reveló que en promedio una tasa impositiva un 1\% mayor reducía en $2,3 \%$ el nivel declarado de rentabilidad antes de deducir los impuestos.

Se ha aducido con frecuencia que una forma de minimizar la asignación abusiva de precios de transferencia como la ya mencionada consiste en exigir la formación de empresas mixtas (joint ventures), ya que es muy difícil que los socios locales acepten la transferencia de grandes cantidades de ingresos al exterior. Pero la liberalización internacional de los códigos de inversión está haciendo cada vez más difícil imponer esa exigencia a las empresas transnacionales. Por lo demás, incluso cuando existen socios locales, a menudo no se les da información sobre la estructura de los costos. El verdadero nivel de rentabilidad es, pues, sumamente difícil de evaluar. Como comentó un ex director ejecutivo de la Compañía Nacional de Petróleo de Nigeria, una empresa mixta asociada a la Shell, 'no hemos podido supervisar debidamente los costos de sus operaciones [las de la Shell], y podríamos concluir que lo que hace que estas sociedades sigan funcionando no es el margen teórico sino las ganancias que incorporan a sus costos' (Frynas, 1998, p.20). 


\section{IV}

\section{Los impuestos unitarios como forma de combatir la evasión fiscal}

Otra solución podría ser gravar los resultados consolidados de las empresas transnacionales y distribuir la carga tributaria, utilizando alguna variable fácil de cuantificar (como las ventas, el capital fijo u otra) en lugar de las ganancias. En la práctica, la fórmula más común es la de prorratear los ingresos de la sociedad sobre la base de la participación media del país en el total de las ventas, el capital fijo y la remuneración de la mano de obra. Expresado en términos más formales, si $\square$ es el total de las ganancias de una transnacional, la ganancia atribuida al país $j$ para efectos impositivos, $\ulcorner$, es

$$
\pi j=\left(\alpha_{\mathrm{J}}^{\mathrm{P}} \frac{\mathrm{P}_{\mathrm{i}}}{\mathrm{P}}+\alpha_{\mathrm{J}}^{\mathrm{L}} \frac{\mathrm{L}_{\mathrm{i}}}{\mathrm{L}}+\alpha_{\mathrm{J}}^{\mathrm{S}} \frac{\mathrm{S}_{\mathrm{i}}}{\mathrm{S}}\right) \pi
$$

donde $P$ es el total de los activos de la sociedad, $L$ es el total de la mano de obra empleada y $S$ es el total de las ventas de la empresa transnacional, y $P_{j}$ y $L_{j}$ y $S_{j}$ son los activos, la mano de obra empleada y las ventas dentro de la jurisdicción impositiva del país en cuestión, mientras que $\alpha_{j}^{\mathrm{f}}$ es la ponderación de cada factor $f$ en el país $j$ en el impuesto total. En la práctica, el método de ponderación más utilizado es el de adjudicar un tercio a cada componente.

Con impuestos unitarios de este tipo se eliminaría el incentivo para transferir las ganancias a jurisdicciones con impuestos bajos. Huelga decir que una propuesta de esta índole provocaría una airada reacción de las empresas transnacionales, y se sabe por experiencia que estas compañías son capaces de cabildear enérgicamente en torno a cualquier tema que pueda afectar sus intereses. Más allá de la conveniencia política, sin embargo, hay pocos motivos para mantener estos asuntos fuera de la agenda pública: las iniciativas generadoras de ingresos como ésta son esenciales para fortalecer la posición fiscal del Estado en los países en desarrollo, y también pueden originar importantes beneficios para los países desarrollados. En un estudio reciente de Shackelford y Slemrod (1998), basado en los informes financieros de 46 empresas transnacionales con base en los Estados Unidos, se estima que la aplicación de un impuesto unitario en ese país hubiese aumentado las obligaciones tributarias de dichas empresas en los Estados Unidos en un 38\%, y que en el caso de las empresas de petróleo y gas ese aumento hubiese sido mucho mayor, del $81 \%$.

Además, aunque las empresas transnacionales de partida puedan resistirse a admitirlo, un sistema de impuestos unitarios tendría ciertas ventajas incluso para ellas mismas. La manipulación de los precios de transferencia afecta la capacidad de la empresa para evaluar el desempeño de sus filiales: cuanto más recurre a esa práctica, más difícil se le hace determinar si la rentabilidad de la filial se debe al nivel de productividad, o si es simplemente un artificio contable. Por lo tanto, el manejo de los precios de transferencia distorsiona en definitiva la estructura de incentivos dentro de la empresa. Una filial que reciba instrucciones de cobrar un precio de transferencia alto por un bien o servicio suministrado a otra filial dará la impresión de tener un mejor desempeño del que realmente tiene, mientras que la filial que compra el bien o servicio tendrá aparentemente peores resultados. A menos que se reconozca este sesgo intrínseco al hacer las evaluaciones de desempeño, se pueden producir graves distorsiones en los sistemas de incentivos administrativos (Hill, 2000, p.625). En este sentido, las propias empresas transnacionales se verían beneficiadas por la mayor transparencia que se derivaría de un sistema de impuestos unitarios. Los impuestos unitarios también permitirían a las empresas concentrarse en fortalecer sus ventajas competitivas, en lugar de desperdiciar mucho tiempo y recursos administrativos valiosos en idear estrategias de evasión fiscal. Debido a la simplicidad del sistema, los impuestos unitarios también pueden reducir enormemente los gastos de contabilidad. Como ha dicho Philip Gillett, contralor de impuestos en el Investment Company Institute (ICI), 'Desde el punto de vista comercial, la asignación de precios de transferencia no tiene sentido. Nos obliga a pasar mucho tiempo haciendo cosas absurdas desde el punto de vista empresarial... Las empresas quieren organizarse como 
si hubiera un solo mercado de productos regionales. En cambio, son los impuestos los que están determinando la forma en que ellas se organizan' (The Economist, 2000, p.14).

Además, es claramente injusto que las diferencias en el desempeño de las sociedades dependan hasta tal punto de la capacidad de sus contadores para reducir el pago de impuestos. El estudio de McIntyre y Nguyen (2000) ya mencionado reveló que los competidores de diversas industrias afrontaban tasas impositivas efectivas muy variadas. Por ejemplo, tanto Maytag como General
Electric fabrican electrodomésticos de cocina, pero mientras Maytag pagó el 35\% de sus ganancias por concepto de impuestos entre 1996 y 1998, General Electric pagó solamente el 8,1\%. De manera similar, los laboratorios Abbot y Pfizer trabajan en el sector farmacéutico, pero mientras el primero pagó casi el $29 \%$ de sus ganancias por concepto de impuestos entre 1996 y 1998, el segundo pagó apenas el 3,1\%. Estos ejemplos reflejan trucos competitivos que resultan injustos para los accionistas. Los impuestos unitarios permitirían competir en condiciones más equitativas.

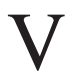

\section{Los impuestos unitarios en la práctica}

Nunca es fácil introducir reformas tributarias. Los regímenes impositivos tienden a evolucionar de manera desordenada, y si bien los resultados pueden a menudo parecer irracionales e inequitativos a quienes los miran desde afuera, dentro de ellos se crean intereses políticos que suelen detener el avance de reformas bien intencionadas. La experiencia del economista Nicholas Kaldor es aleccionadora en ese sentido. Durante las décadas de 1950 y 1960, Kaldor participó en muchas misiones relacionadas con impuestos en países en desarrollo. Si bien muchas de sus propuestas se basaban en sólidos principios económicos y podrían haber sido el punto de partida para la implantación de un régimen tributario más equitativo, pocos países estuvieron dispuestos a seguir sus recomendaciones tributarias, o estuvieron en posición de poder hacerlo. En Ghana, por ejemplo, el Primer Ministro Nkrumah le pidió a Kaldor que lo asesorara sobre la situación presupuestaria y el régimen tributario durante la crisis económica que afectó a ese país en 1961. Kaldor quería reformar el régimen impositivo aplicable a las sociedades para evitar que las empresas extranjeras eludieran el pago de impuestos mediante la asignación de precios de transferencia, e introducir un plan de ahorro obligatorio para respaldar los esfuerzos de desarrollo. Sin embargo, las propuestas resultaron insostenibles desde el punto de vista político, y generaron agitación política y una huelga de trabajadores (Thirlwall, 2003, pp. 522-524).

Episodios como este, que llaman a la cautela, no son sin embargo motivo suficiente para no presionar en aras de un cambio. Los impuestos unitarios no son algo nuevo, ya se han probado antes, de modo que es posible recoger enseñanzas importantes de experiencias anteriores. ${ }^{20}$ De hecho, una de las ironías del proceso de globalización es que los impuestos unitarios se pusieron en práctica por primera vez en el país que es por sí solo la fuente más importante de IED del mundo: los Estados Unidos. En efecto, ninguno de los estados de ese país trata de medir, para fines tributarios, las ganancias que obtienen en uno de ellos las empresas que operan en varios estados, exigiéndoles que lleven una contabilidad separada. En cambio, todos los estados de la nación utilizan algún tipo de fórmula para prorratear las ganancias que obtienen las empresas en todo el país (y en algunos casos en todo el mundo) y adjudicarlas a cada estado (Shackelford y Slemrod, 1998, p.41). En la década de 1980 fueron 12 los estados del país que adoptaron un impuesto unitario a nivel mundial. ${ }^{21}$ Los legisladores estaduales estaban conscientes de la facilidad con que las empresas transnacionales podían evadir los impuestos estaduales sobre las ganancias, simplemente transfiriendo ingresos a otros estados donde la presión fiscal fuera menor. Los contralores estaduales fueron pues los defensores de los impuestos unitarios como forma de minimizar la evasión fiscal mediante la asignación de precios de transferencia.

\footnotetext{
${ }^{20}$ Hasta donde sabemos, el primer autor que argumentó que los países debían abandonar el método de contabilidad separada para adoptar una fórmula de prorrateo fue Musgrave (1973). ${ }^{21}$ El relato de esta experiencia de los Estados Unidos en la aplicación de los impuestos unitarios se extrajo en gran parte de Glickman y Woodward (1989, pp. 210-213). Véase también Hines (1996b).
} 
La reacción política en contra de estas medidas fue casi inmediata. La constitucionalidad de este método de tributación aplicado por los estados fue cuestionada en los tribunales en numerosas ocasiones. Por lo menos 20 países presentaron protestas oficiales ante los Estados Unidos en representación de empresas transnacionales, aduciendo que los impuestos unitarios sometían a las empresas extranjeras a una doble tributación, requerían procedimientos contables engorrosos y obligaban a las empresas transnacionales a preparar informes detallados sobre sus actividades mundiales. En California, uno de los lugares favoritos para penetrar en el mercado estadounidense, la legislación sobre impuestos unitarios provocó una respuesta particularmente adversa. Como ha señalado Vernon (1998, p.42), la iniciativa de California de abandonar toda pretensión de calcular las obligaciones tributarias utilizando precios normales de mercado para las transferencias dentro de una misma empresa 'horrorizó a la comunidad internacional, casi como si las insensatas autoridades estaduales estuvieran infringiendo algún dogma religioso'. ${ }^{22}$ La intensa presión ejercida por las empresas transnacionales y los gobiernos extranjeros llevó finalmente a todos los estados, salvo Alaska, a derogar las leyes de impuestos unitarios.

No obstante, la enseñanza que puede recogerse de la experiencia estadounidense no es que los impuestos unitarios sean inviables, o políticamente indefendibles. Por el contrario, el caso de los Estados Unidos demuestra la necesidad de aplicar impuestos unitarios a nivel general. Como sólo una pequeña mayoría de los estados de ese país adoptaron los impuestos unitarios, las empresas transnacionales lograron generar antagonismo entre estados, simplemente amenazándolos con retirar sus inversiones. En definitiva, esta presión benefició a las empresas transnacionales extranjeras. Uno de los primeros estados en claudicar fue Oregón, que derogó sus impuestos unitarios en 1984. El incidente que lo llevó a revisar la política tributaria fue la pérdida de una importante inversión japonesa de los fabricantes de automóviles Mitsubishi, que finalmente se trasladó

\footnotetext{
${ }^{22}$ En este caso, el escándalo fue en gran medida exagerado. Por ejemplo, a pesar de la bien conocida antipatía de las empresas transnacionales basadas en Japón por la legislación californiana sobre impuestos unitarios, California fue el estado que logró atraer más inversiones japonesas. De las 295 nuevas fábricas anunciadas por compañías japonesas desde principios del decenio de 1970 hasta 1985, fueron 109 (37\%) las que se instalaron en el Lejano Oeste, predominantemente en California (Glickman y Woodward, 1989, p.210).
}

a Carolina del Norte. ${ }^{23}$ La campaña en contra de los impuestos unitarios culminó con un enfrentamiento en Sacramento, donde los cabilderos de las empresas transnacionales argumentaron que California perdería dinero de inversiones si no se derogaba el método de cálculo. Para fines de la década de 1980, solamente Alaska había logrado resistir a la presión de capitular y derogar el código de impuestos unitarios. ${ }^{24}$

Cabe argumentar, sin embargo, que la situación podría haber sido muy diferente si se hubieran adoptado los impuestos unitarios a nivel mundial en los 50 estados simultáneamente. El mercado de los Estados Unidos es tan importante para las empresas extranjeras que no cabría concebir una retirada masiva de las inversiones extranjeras en él. Lo mismo puede decirse de la Unión Europea (UE): cualquier Estado miembro que actuara por sí solo probablemente tendría que enfrentar una andanada de quejas y amenazas de las empresas transnacionales. Pero una acción simultánea concertada por los 15 Estados miembros haría muy difícil para esas empresas adoptar cualquier medida evasiva. Por ejemplo, a la UE le corresponde actualmente alrededor del $48 \%$ de las ventas mundiales y el $56 \%$ del valor agregado producido por filiales estadounidenses en el exterior. ${ }^{25}$ Para la mayoría de las empresas transnacionales sería un importante error estratégico retirarse de un mercado de esa magnitud sólo para evitar el pago de impuestos.

Obviamente, la situación de los países en desarrollo es más delicada; si tratan de imponer nuevas medidas tributarias, estarán mucho más expuestos a sufrir las consecuencias de las represalias de las empresas transnacionales. Sin embargo, aun en este caso la experiencia indica que dichas empresas suelen ladrar

\footnotetext{
${ }^{23}$ En efecto, en un informe preparado para la administración del estado de Oregón sobre los motivos de la pérdida del proyecto y su traslado a Carolina del Norte se llegó a la conclusión de que, en definitiva, Oregón había perdido la planta porque la proximidad del mercado había sido un factor clave en el proceso de decisión, y Mitsubishi quería instalarse cerca del mercado de la costa este. Se concluyó asimismo que 'si bien el impuesto unitario fue evaluado cuidadosamente por los japoneses, no parece haber sido un factor crítico en su decisión de construir la planta en Carolina del Norte en lugar de Salem' (citado en Glickman y Woodward, 1989, p.212). ${ }^{24}$ California, Montana y Dakota del Norte también siguen aplicando regímenes de impuestos unitarios a nivel mundial, pero en esos casos su uso es opcional para los contribuyentes (Hines, 1996b, p.1079). ${ }^{25}$ Datos del Departamento de Comercio de los Estados Unidos, Encuesta de referencia de 1999 sobre la inversión directa estadounidense en el exterior [http://www.bea.doc.gov/ bea/ai/newiid.htm].
} 
más fuerte de lo que muerden. ${ }^{26}$ Los casos en que se han retirado realmente de un país son relativamente pocos. Incluso cuando se han adoptado medidas bastante draconianas contra ellas en países en desarrollo, en su mayoría se han quedado donde estaban. ${ }^{27}$ De todos modos, es probable que las empresas que saldrían perdiendo con la introducción de un sistema de impuestos unitarios serían precisamente aquellas que

\section{VI}

\section{Conclusiones}

En este artículo se han presentado argumentos a favor de crear un nuevo sistema de impuestos unitarios sobre las ganancias de las empresas transnacionales, como una manera de contribuir a financiar los gastos en servicios sociales e infraestructura relacionados con el desarrollo. Según cálculos muy preliminares de Oxfam Reino Unido, los ingresos que pierden actualmente los países en desarrollo debido a la evasión de impuestos por estas sociedades ascienden como mínimo a 35.000 millones de dólares anuales. La asignación de precios de transferencia no es el único pero sí uno de los principales mecanismos que utilizan las empresas transnacionales para reducir su "exposición" tributaria. Los impuestos unitarios eliminarían el incentivo para recurrir a él.

Al mismo tiempo, es necesario destacar que los impuestos unitarios no impiden a los países o regiones ofrecer tasas impositivas más bajas. Por ejemplo, como parte de la política regional podría considerarse aceptable la posibilidad de rebajar la tasa del impuesto sobre las sociedades con el propósito de evitar una concentración excesiva de la actividad económica, y de extender los beneficios del crecimiento económico a zonas periféricas

\footnotetext{
${ }^{26}$ Por ejemplo, en el Presupuesto de marzo de 2000, el gobierno británico anunció la prohibición de utilizar sociedades mixtas, que permitían a las empresas transnacionales con sede en el Reino Unido reducir sus obligaciones tributarias totales (Grant, 2000). El gobierno británico estimó que esta medida costaría a esas empresas unos 300 millones de libras esterlinas en pagos de impuestos adicionales. Pero la cifra fue enérgicamente refutada por los cabilderos de las empresas, que alegaron que el costo total podría ascender a varios miles de millones de libras. Pero hasta el Financial Times manifestó haber captado un "olorcillo a histeria" en torno a las evaluaciones del impacto de los cambios realizadas por el sector privado. En este caso, la única concesión que ofrecía el gobierno era una postergación de nueve meses para la aplicación de las nuevas medidas. Este caso es
}

los países en desarrollo no deberían interesarse en atraer: empresas sumamente móviles a las que no les importan demasiado los servicios (como la educación, por ejemplo) existentes en los países receptores, y que probablemente no harían una contribución importante al desarrollo. ${ }^{28}$ En este sentido, un sistema de impuestos unitarios podría incluso mejorar la calidad de la inversión extranjera recibida. menos desarrolladas. De manera similar, los países en desarrollo podrían seguir ofreciendo tasas impositivas más bajas como forma de atraer inversiones con movilidad internacional.

La ventaja del sistema de impuestos unitarios radicaría en su transparencia intrínseca, ya que haría mucho más difícil para las empresas eludir su responsabilidad fiscal. Cabría esperar asimismo que los directivos de las empresas comprendieran que un régimen impositivo justo redundaría a largo plazo en beneficio de sus propios intereses. Un sistema de impuestos unitarios no solamente simplificaría sus prácticas contables y les permitiría dedicar un tiempo administrativo valioso a fortalecer sus ventajas competitivas, sino que también les traería muchos otros beneficios derivados del gasto público en infraestructura, programas sociales, etc. Al mejorar la salud y la educación de sus empleados, las empresas transnacionales podrían también salir muy beneficiadas por un aumento de la productividad. Los vínculos son por supuesto indirectos, y los beneficios serían a largo plazo, pero la preferencia de los inversionistas directos por las economías de mercado desarrolladas con altos

particularmente interesante porque demuestra hasta qué punto un gobierno supuestamente favorable a las empresas, como la administración Blair, es capaz de hacer retroceder a empresas grandes si actúa de manera concertada y está convencido de la validez de sus argumentos.

27 Los ejemplos que se citan más comúnmente de empresas transnacionales que se retiran de un país en desarrollo son la salida de IBM, Coca-Cola y Exxon de la India en la década de 1970. Pero en ese caso la controversia estuvo vinculada con las restricciones impuestas por el gobierno indio a la propiedad mayoritaria y no tenía relación alguna con cuestiones de tributación.

${ }^{28}$ Agradezco a Arthur MacEwan este punto de vista. 
niveles de protección social sugiere sin duda alguna que las empresas responsables también están conscientes de estos beneficios potenciales y dispuestas a hacer una justa contribución para financiarlas.

Si bien es obviamente deseable, cabe destacar que la adopción de un sistema de impuestos unitarios por un solo país o un grupo de países no exige en principio una mayor coordinación entre las autoridades impositivas ni negociaciones internacionales exhaustivas. Los accionistas de las sociedades siempre piden información sobre los resultados consolidados, dondequiera que se encuentre registrada la empresa transnacional. La aplicación de métodos contables diferentes implica por supuesto que las ganancias declaradas variarán según el lugar de inscripción de la sociedad. Para que un sistema unitario funcione con eficiencia, es conveniente que todas las sociedades utilicen las mismas prácticas contables. No obstante, la falta de un sistema de contabilidad totalmente homogéneo a nivel internacional no impediría la aplicación de un impuesto unitario por cualquier país o grupo de países que deseen aplicarlo -aunque puedan querer presionar a las empresas transnacionales dentro de su territorio para que respeten los principios contables generalmente aceptados de los Estados Unidos, o las normas del Comité Internacional de Estándares Contables (IASB), con sede en Londres- ${ }^{29}$

Afortunadamente, la preocupación por la evasión fiscal es compartida tanto por los países en desarrollo como por los países industrializados. La globalización de los mercados está generando el temor de que las formas tradicionales de recaudación fiscal peligren cada vez más. Por lo tanto, una iniciativa para resolver estos problemas tiene más probabilidades de triunfar. La preocupación por las tendencias actuales se ha expresado incluso en el seno del FMI, una institución que no se asocia normalmente a una preocupación por los efectos de las tasas impositivas bajas. En un trabajo reciente preparado por un economista del Fondo (Tanzi, 2000), se señala que 'si bien la casa fiscal continúa en pie y parece sólida, uno puede ver muchas termitas fiscales muy ocupadas carcomiendo sus cimientos'. La habilidad de las empresas transnacionales para embarcarse en actividades ilegales de manipulación de precios de transferencia es, sin lugar a dudas, una de las termitas fiscales a las que se refiere Tanzi.

\footnotetext{
29 Dependiendo de cuál de estos dos métodos de contabilidad se utilice, las discrepancias en las ganancias declaradas pueden a menudo ser grandes. En el período posterior a los escándalos de Enron y Worldcom, las probabilidades de que en definitiva se impongan las normas del IASB han mejorado considerablemente. Véase The Economist (2002).
}

Es evidente que, con independencia de sus méritos, la propuesta de aplicar impuestos unitarios tropezará con una fuerte oposición de los grupos de cabildeo que defienden los intereses de las empresas. Sin embargo, los argumentos a favor de los impuestos unitarios son lo suficientemente sólidos como para no permitir que esas presiones políticas desvíen a la reforma de sus objetivos. Hasta el momento, todas las iniciativas de reforma de los códigos tributarios han apuntado a eliminar la doble tributación internacional, medidas que los inversionistas internacionales obviamente han apoyado con gran entusiasmo. En vista de las evidencias que indican que las tasas impositivas efectivas que pagan las empresas transnacionales están disminuyendo, este énfasis es claramente injusto. En tales circunstancias, la aplicación de impuestos unitarios daría un gran impulso a la reforma. La legislación internacional sentaría las bases para que los estándares se nivelaran hacia arriba, y no hacia abajo, como se ha tendido a hacer hasta ahora. Una forma de lograr que la propuesta sea políticamente más aceptable podría consistir en reducir las tasas del impuesto sobre las sociedades a través de los impuestos unitarios. Las empresas transnacionales podrían estar más dispuestas a aceptar un sistema de impuestos unitarios si las tasas básicas fueran más bajas. Desde el punto de vista de los gobiernos también podría ser preferible tener una tasa más baja, pero una recaudación más eficiente.

La Unión Europea está en condiciones favorables para tomar medidas a este respecto. Si bien hasta ahora los progresos han sido lentos, hay un consenso cada vez mayor en cuanto a la necesidad de adoptar medidas para evitar la competencia tributaria y la evasión fiscal entre los Estados miembros (Radaelli, 1999). La adopción de un sistema de impuestos unitarios a nivel de toda Europa daría el impulso necesario a la reforma tributaria. La acción de la UE en este sentido sentaría un precedente favorable que podrían imitar posteriormente otros países. Puesto que aproximadamente el $85 \%$ de las empresas transnacionales se forman en países de la OCDE, esta organización también constituye un foro apropiado para proponer la introducción de impuestos unitarios. Hasta el momento, los intentos de aprobar un marco jurídico internacional para la IED, como el malogrado Acuerdo Multilateral sobre Inversiones (AMI) de la OCDE, han contribuido únicamente a flexibilizar los controles aplicables a las empresas extranjeras. En este contexto, una propuesta de reforzar la capacidad de los Estados nacionales para recaudar mediante impuestos una justa proporción de las ganancias derivadas de las actividades de las empresas 
transnacionales podría ser suficiente para inclinar la balanza a favor de cualquier acuerdo futuro: la iniciativa recibiría un apoyo más amplio, y los países en desarrollo sentirían que no sólo están haciendo concesiones a esas empresas, sino también recibiendo algo a cambio de ese acuerdo. Iniciativas audaces como ésta son sin duda necesarias para lograr una mayor justicia y equidad en el sistema económico mundial, y deberían ser parte indispensable de cualquier propuesta futura.

Apéndice

Mundo: Tasas impositivas efectivas pagadas por las filiales de propiedad mayoritaria de empresas estadounidenses, 1983 y 1999

(En millones de dólares y porcentajes)

\begin{tabular}{|c|c|c|c|c|c|c|c|}
\hline & \multicolumn{3}{|c|}{1983} & \multicolumn{3}{|c|}{1999} & \multirow{2}{*}{$\begin{array}{c}\text { Cambio } \\
\text { en la tasa } \\
\text { impositiva } \\
\text { efectiva } \\
\text { 1983-1999 (\%) }\end{array}$} \\
\hline & $\begin{array}{l}\text { Impuestos } \\
\text { extranjeros } \\
\text { sobre los } \\
\text { ingresos (1) }\end{array}$ & $\begin{array}{c}\text { Ingresos } \\
\text { netos } \\
(2)\end{array}$ & $\begin{array}{c}\text { Tasa } \\
\text { impositiva } \\
\text { efectiva }(\%) \\
(1) /[(1)+(2)]\end{array}$ & $\begin{array}{l}\text { Impuestos } \\
\text { extranjeros } \\
\text { sobre los } \\
\text { ingresos (1) }\end{array}$ & $\begin{array}{c}\text { Ingresos } \\
\text { netos } \\
(2)\end{array}$ & $\begin{array}{c}\text { Tasa } \\
\text { impositiva } \\
\text { efectiva }(\%) \\
(1) /[(1)+(2)]\end{array}$ & \\
\hline Todos los paises & 30122 & 30600 & 49,6 & 45791 & 160490 & 22,2 & $-55,3$ \\
\hline Canadá & 3700 & 5588 & 39,8 & 6676 & 14951 & 30,9 & $-22,5$ \\
\hline $\begin{array}{l}\text { Europa } \\
\text { Austria } \\
\text { Bélgica } \\
\text { Dinamarca } \\
\text { Finlandia } \\
\text { Francia }\end{array}$ & $\begin{array}{r}12075 \\
47 \\
265 \\
65 \\
38 \\
736\end{array}$ & $\begin{array}{r}12503 \\
80 \\
453 \\
175 \\
54 \\
666\end{array}$ & $\begin{array}{l}49,1 \\
37,0 \\
36,9 \\
27,1 \\
41,3 \\
52,5\end{array}$ & $\begin{array}{r}22464 \\
259 \\
916 \\
234 \\
161 \\
2089\end{array}$ & $\begin{array}{r}91467 \\
599 \\
2570 \\
790 \\
282 \\
3610\end{array}$ & $\begin{array}{l}19,7 \\
30,2 \\
26,3 \\
22,9 \\
36,3 \\
36,7\end{array}$ & $\begin{array}{l}-59,9 \\
-18,4 \\
-28,8 \\
-15,6 \\
-12,0 \\
-30,2\end{array}$ \\
\hline $\begin{array}{l}\text { Alemania } \\
\text { Grecia } \\
\text { Irlanda } \\
\text { Italia } \\
\text { Luxemburgo } \\
\text { Países Bajos }\end{array}$ & $\begin{array}{r}1316 \\
13 \\
31 \\
488 \\
32 \\
486\end{array}$ & $\begin{array}{r}1766 \\
25 \\
1090 \\
744 \\
88 \\
494\end{array}$ & $\begin{array}{r}42,7 \\
34,2 \\
2,8 \\
39,6 \\
26,7 \\
49,6\end{array}$ & $\begin{array}{r}3513 \\
153 \\
1141 \\
1869 \\
100 \\
1825\end{array}$ & $\begin{array}{r}8375 \\
204 \\
13147 \\
2235 \\
3906 \\
15669\end{array}$ & $\begin{array}{r}29,6 \\
42,9 \\
8,0 \\
45,5 \\
2,5 \\
10,4\end{array}$ & $\begin{array}{r}-30,8 \\
25,3 \\
188,8 \\
15,0 \\
-90,6 \\
-79,0\end{array}$ \\
\hline $\begin{array}{l}\text { Noruega } \\
\text { Portugal } \\
\text { España } \\
\text { Suecia } \\
\text { Suiza } \\
\text { Turquía } \\
\text { Reino Unido } \\
\text { Otros }\end{array}$ & $\begin{array}{r}2197 \\
25 \\
137 \\
132 \\
233 \\
26 \\
5800 \\
2842\end{array}$ & $\begin{array}{r}827 \\
29 \\
16 \\
169 \\
1504 \\
39 \\
4197 \\
2805\end{array}$ & $\begin{array}{l}72,7 \\
46,3 \\
89,5 \\
43,9 \\
13,4 \\
40,0 \\
58,0 \\
50,3\end{array}$ & $\begin{array}{r}1022 \\
258 \\
899 \\
424 \\
653 \\
127 \\
6266 \\
165\end{array}$ & $\begin{array}{r}1052 \\
939 \\
2439 \\
1617 \\
10713 \\
118 \\
22602 \\
460\end{array}$ & $\begin{array}{r}49,3 \\
21,6 \\
26,9 \\
20,8 \\
5,7 \\
51,8 \\
21,7 \\
26,4\end{array}$ & $\begin{array}{r}-32,2 \\
-53,4 \\
-69,9 \\
-52,6 \\
-57,2 \\
29,6 \\
-62,6 \\
-47,5\end{array}$ \\
\hline $\begin{array}{l}\text { América Latina y otros } \\
\text { paises del hemisferio } \\
\text { occidental }\end{array}$ & 2509 & 5129 & 32,8 & 4481 & 26000 & 14,7 & $-55,2$ \\
\hline $\begin{array}{l}\text { América del Sur } \\
\text { Argentina } \\
\text { Brasil } \\
\text { Chile } \\
\text { Colombia } \\
\text { Ecuador } \\
\text { Perú } \\
\text { Venezuela } \\
\text { Otros }\end{array}$ & $\begin{array}{r}1648 \\
47 \\
740 \\
59 \\
185 \\
- \\
125 \\
196 \\
-\end{array}$ & $\begin{array}{r}1003 \\
392 \\
268 \\
50 \\
125 \\
61 \\
119 \\
-41 \\
28\end{array}$ & $\begin{array}{r}62,2 \\
10,7 \\
73,4 \\
54,1 \\
59,7 \\
- \\
51,2 \\
126,5 \\
-\end{array}$ & $\begin{array}{r}1540 \\
375 \\
553 \\
172 \\
227 \\
25 \\
83 \\
39 \\
66\end{array}$ & $\begin{array}{r}3012 \\
350 \\
880 \\
586 \\
475 \\
27 \\
14 \\
642 \\
37\end{array}$ & $\begin{array}{r}33,8 \\
51,7 \\
38,6 \\
22,7 \\
32,3 \\
48,1 \\
85,6 \\
5,7 \\
64,1\end{array}$ & $\begin{array}{r}-45,6 \\
383,1 \\
-47,4 \\
-58,1 \\
-45,8 \\
- \\
67,0 \\
-95,5 \\
-\end{array}$ \\
\hline $\begin{array}{c}\text { América Central } \\
\text { Costa Rica } \\
\text { Honduras } \\
\text { México } \\
\text { Panamá } \\
\text { Otros }\end{array}$ & $\begin{array}{r}422 \\
- \\
- \\
274 \\
85 \\
62\end{array}$ & $\begin{array}{r}517 \\
- \\
- \\
-229 \\
648 \\
98\end{array}$ & $\begin{array}{r}44,9 \\
- \\
- \\
608,9 \\
11,6 \\
38,8\end{array}$ & $\begin{array}{r}2297 \\
37 \\
22 \\
2179 \\
10 \\
49\end{array}$ & $\begin{array}{r}6979 \\
40 \\
26 \\
4805 \\
1939 \\
170\end{array}$ & $\begin{array}{r}24,8 \\
48,1 \\
45,8 \\
31,2 \\
0,5 \\
22,4\end{array}$ & $\begin{array}{r}-44,9 \\
- \\
- \\
-94,9 \\
-95,6 \\
-42,3\end{array}$ \\
\hline
\end{tabular}




\begin{tabular}{|c|c|c|c|c|c|c|c|}
\hline & & 1983 & & & 1999 & & Cambio \\
\hline & $\begin{array}{l}\text { Impuestos } \\
\text { extranjeros } \\
\text { sobre los } \\
\text { ingresos (1) }\end{array}$ & $\begin{array}{c}\text { Ingresos } \\
\text { netos } \\
(2)\end{array}$ & $\begin{array}{c}\text { Tasa } \\
\text { impositiva } \\
\text { efectiva (\%) } \\
(1) /[(1)+(2)]\end{array}$ & $\begin{array}{l}\text { Impuestos } \\
\text { extranjeros } \\
\text { sobre los } \\
\text { ingresos (1) }\end{array}$ & $\begin{array}{l}\text { Ingresos } \\
\text { netos } \\
(2)\end{array}$ & $\begin{array}{c}\text { Tasa } \\
\text { impositiva } \\
\text { efectiva (\%) } \\
(1) /[(1)+(2)]\end{array}$ & $\begin{array}{c}\text { en la tasa } \\
\text { impositiva } \\
\text { efectiva } \\
1983-1999(\%)\end{array}$ \\
\hline $\begin{array}{l}\text { Otros países del } \\
\text { hemisferio occidental }\end{array}$ & 439 & 3610 & 10,8 & 644 & 16009 & 3,9 & $-64,3$ \\
\hline Ant. Neerlandesas & 221 & 1283 & 14,7 & - & - & - & - \\
\hline Barbados & 7 & 141 & 4,7 & 158 & 1337 & 10,6 & 123,4 \\
\hline Bermudas & 36 & 1664 & 2,1 & 238 & 8175 & 2,8 & 33,6 \\
\hline Rep. Dominicana & 9 & 26 & 25,7 & 15 & 509 & 2,9 & $-88,9$ \\
\hline Trinidad y Tabago & 140 & 100 & 58,3 & - & - & - & - \\
\hline $\begin{array}{l}\text { Islas del Reino Unido } \\
\text { en el Caribe }\end{array}$ & 1 & 286 & 0,3 & 85 & 4817 & 1,7 & 397,7 \\
\hline Otros & 27 & 110 & 19,7 & 148 & 1171 & 11,2 & $-43,1$ \\
\hline $\begin{array}{l}\text { Egipto } \\
\text { Nigeria }\end{array}$ & 1421 & $\begin{array}{l}515 \\
357\end{array}$ & 79,9 & $\begin{array}{r}125 \\
1096\end{array}$ & $\begin{array}{l}461 \\
960\end{array}$ & $\begin{array}{l}21,3 \\
53,3\end{array}$ & $-33, \overline{3}$ \\
\hline Sudáfrica & 272 & 388 & 41,2 & $\begin{array}{r}1090 \\
99\end{array}$ & 169 & 36,9 & $-10,4$ \\
\hline Otros & 4494 & 724 & 86,1 & 720 & 652 & 52,5 & $-39,1$ \\
\hline Oriente medio & 2162 & 516 & 80,7 & 1022 & 1343 & 43,2 & $-46,5$ \\
\hline Arabia Saudita & 461 & 104 & 81,6 & 29 & 206 & 12,3 & $-84,9$ \\
\hline Emir. Árabes Unidos & 1618 & 292 & 84,7 & 133 & 163 & 44,9 & $-47,0$ \\
\hline Israel & 53 & 90 & 37,1 & 110 & 342 & 24,3 & $-34,3$ \\
\hline Otros & 29 & 31 & 48,3 & 751 & 632 & 54,3 & 12,3 \\
\hline Asia y el Pacífico & 7810 & 9261 & 45,8 & 9054 & 24126 & 27,3 & $-40,4$ \\
\hline Australia & 989 & 597 & 62,4 & 1020 & 3157 & 24,4 & $-60,8$ \\
\hline China & - & - & & 249 & 912 & 21,4 & - \\
\hline Hong Kong & 73 & 662 & 9,9 & 450 & 4111 & 9,9 & $-0,7$ \\
\hline India & 32 & 21 & 60,4 & 134 & -27 & 125,2 & 107,4 \\
\hline Indonesia & 2383 & 1779 & 57,3 & 1069 & 2249 & 32,2 & $-43,7$ \\
\hline Japón & 764 & 776 & 49,6 & 4136 & 4848 & 46,0 & $-7,2$ \\
\hline Malasia & 213 & 431 & 33,1 & 228 & 1601 & 12,5 & $-62,3$ \\
\hline República de Corea & 31 & 88 & 26,1 & 361 & 787 & 31,4 & 20,7 \\
\hline Filipinas & 83 & 59 & 58,5 & 214 & 724 & 22,8 & $-61,0$ \\
\hline Nueva Zelandia & 37 & 74 & 33,3 & 78 & 106 & 42,4 & 27,2 \\
\hline Singapur & 109 & 631 & 14,7 & 524 & 3905 & 11,8 & $-19,7$ \\
\hline Taiwán (Prov. china) & 43 & 184 & 18,9 & 297 & 980 & 23,3 & 22,8 \\
\hline Tailandia & 36 & 40 & 47,4 & 218 & 647 & 25,2 & $-46,8$ \\
\hline Otros & 3017 & 3919 & 43,5 & 78 & 127 & 38,0 & $-12,5$ \\
\hline Internacional & 104 & 384 & 21,3 & 55 & 360 & 13,3 & $-37,8$ \\
\hline Addenda: & & & & & & & \\
\hline Unión Europea ${ }^{a}$ & 9232 & 9698 & 48,8 & 20106 & 78984 & 20,3 & $-58,4$ \\
\hline $\mathrm{OPEP}^{\mathrm{b}}$ & 8342 & 2690 & 75,6 & 2996 & 4648 & 39,2 & $-48,2$ \\
\hline Países desarrollados ${ }^{\mathrm{c}}$ & 17565 & 19538 & 47,3 & 34374 & 114529 & 23,1 & $-51,2$ \\
\hline Países en desarrollo ${ }^{\mathrm{d}}$ & 12557 & 11062 & 53,2 & 11417 & 45961 & 19,9 & $-62,6$ \\
\hline
\end{tabular}

Fuente: Elaboración propia con datos del Departamento de Comercio de los Estados Unidos [http://www.bea.doc.gov/bea/ai/newiid.htm].

a Constituida por 10 países en 1983 y 15 países en 1999.

b Organización de Países Exportadores de Petróleo.

c Europa, Canadá, Australia, Nueva Zelandia y Japón.

d Los países en desarrollo abarcan el resto del mundo. 
Altshuler R., H. Grubert y S. Newlon (1998): Has US Investment Abroad Become More Sensitive to Tax Rates?, NBER Documento de Trabajo, № 6383, Cambridge, Massachusetts, National Bureau of Economic Research.

Bayliss, K. y D. Hall (2001): Enron: A Corporate Contribution to Global Inequality, Londres, Public Services International Research Unit, University of Greenwich, junio [www.psiru.org].

Bergsten, C. (1974): Multinationals: the games and the rules. Coming investment wars?, Foreign Affairs, vol. 53, № 1, Nueva York, Consejo de Relaciones Exteriores, octubre.

Caves, R. (1996): Multinational Enterprise and Economic Analysis, segunda edición, Cambridge, Massachusetts, Cambridge University Press.

Dicken, P. (1998): Global Shift-Transforming the World Economy, Londres, Paul Chapman Publishing Ltd.

Eden, L. (1998): Taxing Multinationals, Toronto, University of Toronto Press.

El país (2001): El autoritarismo amenaza a Latinoamérica si no se resuelven los graves problemas sociales, 11 de mayo.

Elson, D. (1995): Transnational corporations: dominance and dependency in the world economy, en S. Corbridge (comp.), Development Studies: A Reader, Londres, Arnold, (publicado originalmente en 1988).

Fitzgerald, V. (2001): Regulating Large International Firms, QEH Documento de Trabajo Series (QEHWPS64), Oxford, Queen Elizabeth House, enero [http://www2.qeh.ox.ac.uk/ research/qehwp.html].

Frynas, J. (1998): Is Political Instability Harmful to Business? The Case of Shell in Nigeria, Saint Andrews, University of Saint Andrews.

Glickman, N. y D. Woodward (1989): The New Competitors: How Foreign Investors are Changing the U.S. Economy, Nueva York, Basic Books.

Goolsbee, A. y E. Maydew (1998): Coveting the Neighbor's Manufacturing: The Dilemma of State Income Apportionment, NBER Documento de Trabajo, $\mathrm{N}^{\circ}$ 6614, Cambridge, Massachusetts, National Bureau of Economic Research, junio [http://www.nber.org/papers/w6614].

Grant, W. (2000): Globalisation, Big Business and the Blair Government, CSGR Documento de Trabajo, No 58/00, Warwick, Centre for the Study of Globalisation and Regionalisation University of Warwick, agosto [http://www.csgr.org].

Grimwade, N. (2000): International Trade: New Patterns of Trade, Production and Investment, segunda edición, Londres, Routledge.

Haq, M. ul, I. Kaul e I. Grunberg (comps.) (1996): The Tobin Tax. Coping with Financial Volatility, Nueva York, Oxford University Press.

Hill, C. (2000): International Business: Competing in the Global Marketplace, tercera edición, Boston, Irwin McGraw-Hill.

Hines, J. (1996a): Tax Policy and the Activities of Multinational Corporations, NBER Documento de Trabajo, $N^{\circ} 5589$, Cambridge, Massachusetts, National Bureau of Economic Research, mayo.

(1996b): Altered states: taxes and the location of foreign direct investment in America, American Economic Review, vol 86, N ${ }^{\circ} 5$, Nashville, Tennessee, American Economic Association.

Hines, J. y E. Rice (1994): Fiscal paradise: foreign tax havens and American business, Quarterly Journal of Economics, vol. 109, $\mathrm{N}^{\circ}$ 1, Cambridge, Massachusetts, The мIт Press, febrero.

Kozul-Wright, R. y R. Rowthorn (1998): Spoilt for choice? Multinational corporations and the geography of international production, Oxford Review of Economic Policy, vol. 14, № 2, Oxford, Oxford University Press.

Kumar, N. (1999): Explaining the geography and depth of international production: the case of US and Japanese multinational enterprises, Weltwirtschaftliches Archiv, vol. 136, No 3, Kiel, Kiel Institute for World Economics.

Lall, S. y P. Streeten (1977): Foreign Investment, Transnationals and Developing Countries, Londres, MacMillan.

MacEwan, A. (2001): ¿Neoliberalismo o democracia? Estrategia económica, mercados y alternativas para el siglo XXI, Barcelona, Intermón Oxfam.

Madeley, J. (1999): Big Business, Poor Peoples: The Impact of Transnational Corporations on the World's Poor, Londres, Zed Books.

McIntyre, R. y T. Nguyen (2000): Corporate Income Taxes in the 1990s, Washington, D.C., Institute on Taxation and Economic Policy, octubre.

Mehrotra, S., J. Vandemoortele y D. Delamonica (2000): Basic Services for All? Public Spending and the Social Dimensions of Poverty, Florencia, Innocenti Research Centre [http://www.unicef-icdc.org/publications/pdf/basice.pdf].

Mold, A. (2000): Empresas multinacionales, integración europea y las economías periféricas: un análisis de la dinámica espacial del mercado único, tesis de doctorado, Madrid, Facultad de Ciencias Económicas y Empresariales, Universidad Complutense de Madrid.

(2001): Past Experience and Future Perspectives for Foreign Direct Investment in Nigeria, documento de trabajo, DT04/2001, Madrid, Instituto Complutense de Estudios Internacionales [http://www.ucm.es/info/icei/publica/ doctra.html].

Moran, T. (1998): Foreign Direct Investment and Development: The New Agenda for Developing Countries and Economies in Transition, Washington, D.C., Instituto de Economía Internacional.

Morisset, J. y N. Pirnia (2002): How tax policy and incentives affect foreign direct investment: a review, en L. Wells, N. Allen y otros, Using Tax Incentives to Compete for Foreign Investment: Are They Worth the Cost?, Documento de Trabajo, № 15 , Washington, D.C., Corporación Financiera Internacional/Banco Mundial.

Musgrave, P. (1973): International tax base division and the multinational corporation, Public Finance, vol. 27, No 4.

OIT (Organización Internacional del Trabajo) (1997): World Labour Report: Industrial Relations, Democracy and Social Stability, Ginebra.

Oxfam (2000): Tax Havens: Releasing the Hidden Billions for Poverty Eradication, Oxford, Reino Unido.

Poterba, J. (1999): The Rate of Return to Corporate Capital and Factor Shares: New Estimates Using Revised National Income Accounts and Capital Stock Data, NBER Documento de Trabajo, $\mathrm{N}^{\circ}$ 6263, Cambridge, Massachusetts, National Bureau of Economic Research [www.nber.org/papers/w6263].

Radaelli, C. (1999): Harmful tax competition in the EU: policy narratives and advocacy coalitions, Journal of Common Market Studies, vol 37, № 4, Londres, Blackwell Publishers, diciembre.

Shackelford, D. y J. Slemrod (1998): The revenue consequences of using formula apportionment to calculate U.S. and foreignsource income: a firm-level analysis, International Tax and Public Finance, vol. 5, Amsterdam, Kluwer Academic Publishers.

Tanzi, V. (2000): Globalisation and the Future of Social Protection, IMF Documento de Trabajo $N^{\circ} 12$, Washington, D.C., Fondo Monetario Internacional (FMI). 
Altshuler R., H. Grubert y S. Newlon (1998): Has US Investment Abroad Become More Sensitive to Tax Rates?, NBER Documento de Trabajo, $N^{\circ} 6383$, Cambridge, Massachusetts, National Bureau of Economic Research.

Bayliss, K. y D. Hall (2001): Enron: A Corporate Contribution to Global Inequality, Londres, Public Services International Research Unit, University of Greenwich, junio [www.psiru.org].

Bergsten, C. (1974): Multinationals: the games and the rules. Coming investment wars?, Foreign Affairs, vol. 53, № 1, Nueva York, Consejo de Relaciones Exteriores, octubre.

Caves, R. (1996): Multinational Enterprise and Economic Analysis, segunda edición, Cambridge, Massachusetts, Cambridge University Press.

Dicken, P. (1998): Global Shift -Transforming the World Economy, Londres, Paul Chapman Publishing Ltd.

Eden, L. (1998): Taxing Multinationals, Toronto, University of Toronto Press.

El país (2001): El autoritarismo amenaza a Latinoamérica si no se resuelven los graves problemas sociales, 11 de mayo. Elson, D. (1995): Transnational corporations: dominance and dependency in the world economy, en S. Corbridge (comp.), Development Studies: A Reader, Londres, Arnold, (publicado originalmente en 1988).

Fitzgerald, V. (2001): Regulating Large International Firms, QEH Documento de Trabajo Series (QEHWPS64), Oxford,

Queen Elizabeth House, enero [http://www2.qeh.ox.ac.uk/ research/qehwp.html].

Frynas, J. (1998): Is Political Instability Harmful to Business? The Case of Shell in Nigeria, Saint Andrews, University of Saint Andrews.

Glickman, N. y D. Woodward (1989): The New Competitors: How Foreign Investors are Changing the U.S. Economy, Nueva York, Basic Books.

Goolsbee, A. y E. Maydew (1998): Coveting the Neighbor's Manufacturing: The Dilemma of State Income Apportionment, NBER Documento de Trabajo, $\mathrm{N}^{0}$ 6614, Cambridge, 